\title{
A Confucian Look at Internet Censorship in China
}

\author{
Yubo Kou ${ }^{1}$, Bryan Semaan ${ }^{2}$, and Bonnie Nardi ${ }^{3}$ \\ ${ }^{1}$ Purdue University, West Lafayette, IN, USA \\ ${ }^{2}$ School of Information Studies, Syracuse University, NY, USA \\ ${ }^{3}$ Department of Informatics, University of California, Irvine, CA, USA \\ Kou2@purdue.edu, bsemaanesyr.edu, nardi@ics.uci.edu
}

\begin{abstract}
China's Internet censorship practices are sophisticated and pervasive. Academic research and media reports have examined the Chinese government's varied, expansive methods of censorship and Chinese citizens' techniques of subverting them, but little attention has been paid to understanding how Chinese citizens think about censorship in their everyday lives. We conducted a qualitative study of Chinese mainland citizens who circumvented censorship. We found seemingly contradictory attitudes and practices among our participants. They showed proficiency at bypassing censorship, but were sometimes comfortable with censored information. They were willing to share sensitive information with others, but saw the benefits of limiting the public's access to information under certain circumstances. We examine how the complex, nuanced attitudes toward censorship resonate with the classic teachings of Confucianism, China's traditional philosophical and ethical system.
\end{abstract}

Keywords: Censorship $\cdot$ China $\cdot$ Confucianism $\cdot$ social media.

\section{Introduction}

The human-computer interaction community has investigated censorship in online venues with respect to critical issues such as corporate policies, online community norms, and self-disclosure practices [1-4]. In this paper, we focus on censorship in non-Western, non-democratic contexts. We define censorship broadly as government monitoring and suppression of information, communication, media, and/or speech that the government deems objectionable and harmful.

One non-Western country which is often used as a context to explore censorship is China - widely considered to be an authoritarian state with one of the most sophisticated, strict, and comprehensive systems of censorship in the world $[5,6]$. However, previous literature about censorship in China often treats the human-censorship relationship as a "momentary, ahistorical HCI situation" [7], in which censorship exists to oppress and people are expected to resist. Scholars and journalists have investigated the implementation, maintenance, and development of censorship, and measured its effectiveness [5, 8-11]. On the citizen side, the focus has been on techniques for citizens to circumvent censorship [12-16]. However, little attention has been paid to Chinese citizens' varied practices and complex attitudes towards censorship. Con- 
sistent with Kuutti and Bannon's call to the turn to practice [7], this paper concerns Chinese citizens' practices and attitudes related to censorship, as they are embedded in contemporary cultural, historical conditions.

We examine how censorship is viewed and practiced in China, and Chinese attitudes and perspectives towards censorship. We approach these questions through a qualitative study using interviews and document analysis. We interviewed 32 mainland Chinese citizens and collected online interactions made available to us by our informants, triangulating interview and document data. Participants reported both circumventing and supporting censorship-they considered censorship both a constraint and a choice. To frame this finding, we draw on Confucianism-China's traditional ethical and philosophical system dating back over 2500 years. We use it as a lens to describe participants' thoughts and actions. Participants emphasized creative, contextualized adaptation to censorship. They viewed censorship as a government action to protect societal stability, even though they sometimes felt the needed to find ways around it. We argue that participants are embedded in particular philosophical and cultural conditions within which they have developed localized approaches towards censorship. We discuss how sociohistorical factors influenced our participants' experiences with censorship, and we reflect on implications for design.

The Western view of censorship is largely critical and negative. However, here we seek to provide a situated perspective of censorship emerging through routine practice in an environment where censorship is the norm. It is possible that this situated view will not align with the mainstream attitude of the academic community or with certain global perspectives on censorship. We present qualitative data on how Chinese citizens themselves understand and manage censorship.

\section{Background}

\subsection{Confucianism in Contemporary Chinese Society}

Confucius $(551-479 \mathrm{BCE})$ developed a comprehensive system of philosophy and ethics covering morality, politics, economy, family life, and education [17]. Throughout China's history, most dynasties respected, emphasized, and developed Confucianism as the official ideology governing the activities of citizens and the government in the public and private spheres of social life [18-20]. Confucianism continues to have significant impact over Chinese citizens' thoughts and actions [21-24].

Confucianism is conceptualized by its five virtues (五常): benevolence, righteousness, propriety, wisdom, and integrity [20, 25, 26].

The first virtue, Benevolence (仁), describes how people should manifest love and compassion for others. For example, a person might exhibit benevolence by helping disadvantaged individuals or groups.

The second virtue, Righteousness (义), emphasizes how a person's thoughts and actions should conform to his or her own beliefs, and the person should resist temptation. For instance, as our study participants told us, on social media a person should 
speak about public events through reasoned and factual discourse as opposed to relying solely on personal opinions.

The third virtue, Propriety (礼), refers to how a person should respect behavioral norms that maintain social structures, such as hierarchy. In other words, people should value stability and harmony over radicalism in resolving issues. Confucian teachings encourage people to cope with problems in a harmonious way consistent with both propriety and benevolence. People should avoid confrontation and seek peaceful alternatives.

The fourth virtue, Wisdom (智), elaborates how a person should develop knowledge regarding what constitutes right and wrong. For instance, a person should develop knowledge about public events before engaging in public discussion. Acknowledging the differences in people's abilities, experiences, and backgrounds, Confucius believed in diverse methods of educating, accommodating, and serving people, rather than a single universal program of action [26]. For example, Confucius argued that "students have different abilities, backgrounds, and knowledge. There should be different approaches to teaching them" [27]. Confucianism stresses that each person can increase wisdom through education and self-cultivation.

The final virtue, Integrity (信), illustrates how a person's own words and deeds support the collective good. For example, if a person promises to support a collective action in specific ways, he or she should do so.

With a central focus on individual virtues, Confucianism lends itself to a paternalistic governance model that relies on political leaders to promote and live by example, thus embodying the virtues. Confucianism attaches considerable responsibility and duty to the government, stressing that the government should govern through virtuous action, and by taking care of the people [25]. At the same time, Confucianism acknowledges people as the basis of the state. Xunzi $(310-235 B C E)$, a Confucian scholar, compared people and the government to water and a boat, noting that "water can support the boat... water can also overturn the boat" [28]. The government thus must pay close attention to maintaining a harmonious relationship with the people.

According to decades of research [29-34] by the late Duke University political scientist Tianjian Shi and his colleagues, Confucianism has significantly affected contemporary Chinese citizens' political beliefs and values. Shi and $\mathrm{Lu}$ argued that Chinese citizens draw on Confucianism as a means of understanding politics and democracy as a paternalistic model [32]. Confucianism emphasizes the steady hand of elites in delivering governance. Confucianism insists that a government's performance and care for its people are more important than procedural arrangements such as fair elections. Confucianism limits the scope of ordinary citizens' political participation in communicating their concerns to political leaders. Political leaders are expected to make decisions based on their own judgments. Ordinary citizens only oppose the government under extreme conditions, such as when political leaders significantly deviate from expected norms and the virtues of Confucianism. 


\subsection{Manifestations of Confucianism: Censorship Practices in China}

The Chinese government regulates Internet infrastructure, as well as commercial and social use of the Internet [5]. When observing through the lens of Confucianism, we can understand this political system as government leaders having taken it upon themselves to make Internet censorship decisions for the public good.

The Great Firewall, for example, is the primary technical means of restricting information access at the infrastructure level. It blocks foreign websites deemed undesirable by the government such as Facebook and Twitter, regulates access and content, and monitors citizens' Internet use. At the national level, the government controls the gateways to international networks and licenses the operation of Internet service providers. These paternalistic practices manifest in several ways. For example, citizens must use real name to register with Internet service providers [5, 6, 35]. A special Internet police unit enforces the government's censorship regulations $[5,36]$. MacKinnon, a renowned Internet freedom advocate and former journalist, describes a broad range of government tactics, including cyber-attacks against targeted individuals, device and network control, domain-name control, localized disconnection and restriction, surveillance through identity registration, monitoring software, the compliance of Internet companies, and paid online commentators [6].

Censorship laws and regulations are pervasive, yet ambiguous. Businesses and individuals face difficulties in complying. Roberts, a political scientist who studies censorship and propaganda in China, commented that Chinese users often guess what types of information are permissible or forbidden [37]. By using abstract terms such as national interest, social order, and national unity, the government gives itself considerable flexibility in the interpretation of its basic governing principles, as well as the possibility for manipulation $[5,38]$. To comply with the ambiguity of regulations, businesses have adopted sweeping self-censorship mechanisms [5, 39]. For example, both domestic and foreign Internet corporations such as Google and Yahoo! have altered their products to accommodate censorship requirements. A study of keyword blocking on Weibo, the largest micro-blogging service in China, conducted during the 2012 Chinese National Congress election, reported that Weibo actively manipulated and filtered the search results of certain government officials' names [10]. The government has developed censorship strategies that vary across regions. For example, Bamman et al. studied China's content deletion practices on social media and found stricter censorship in outlying provinces such as Tibet, a region the government considers unstable [8].

Censorship targets content perceived to have the potential to spark collective action. King et al. conducted an analysis of deleted social media content on the Chinese Internet [40]. They reported that censorship allowed criticism of government but silenced comments that represented, reinforced, or spurred offline collective action. In an analysis of the Internet's political impact, Givens and MacDonald explained that online exposure of corruption and malfeasance at lower levels of government can help the central government monitor local agents [12]. The government tolerates citizens' online debates around their frustrating experiences with government practices as long as those debates do not develop into offline actions. Such an eventuality could, in the 
government's view, cause societal instability. When viewed from the perspective of Confucianism, the government uses online venues to channel citizens' dissatisfaction to avoid confrontations between citizens and government, and to promote peaceful conflict resolution.

\section{Related Work}

Censorship has been a controversial issue inciting heated debates, with one side stressing the necessity of controlling inappropriate information such as pornography, and the other side upholding principles of Internet freedom [41, 42]. Governments often cite practical reasons for implementing Internet censorship. Singapore, for example, pays considerable attention to censoring information in online political debates which might cause public "panic" [43]. Australia applies censorship with a focus on child pornography sites as well as hate speech and violence [44]. In the humancomputer interaction literature, much discussion is centered on how people censor their own social media behavior for purposes such as privacy, and self-protection [3, 45]. Another strand of research concerns algorithmic censorship [46], where social media algorithms are used to suppress certain topics.

Censorship impacts information seeking. Wilson categorized barriers to information seeking into personal, interpersonal, and environmental [47]. Censorship does not stop information seeking; people often seek alternative information sources [48]. Gunther and Snyder found that people in censored news environments are more critical in selecting news sources [49].

Researchers have reported numerous means by which Chinese citizens circumvent censorship. Citizens use proxy servers to visit blocked sites, and email and instant messaging to share sensitive information [50-53]. They discuss sensitive topics using substitutes for blocked keywords [54, 55]. For example, “harmony 和谐” refers to the government's official ideology that prescribes an ideal society in which each person has sufficient resources to live and grow. People use the term "river crab 河蟹, " a homophone of “和谐” to satirize this ideology [56].

Only a handful of studies have examined perceptions of censorship among Chinese citizens. Wang and Mark [19] surveyed 721 Chinese citizens, finding that respondents' demographic backgrounds, experience of using the Internet, and personality were associated with their attitudes towards censorship. They reported that people with more Internet usage over time tended to accommodate censorship. The authors suggest that we can expect that people in China will increasingly accept censorship as a normal consequence of Internet use. Roberts' [37] study of blogs found that censorship did not deter the spread of information or induce self-censorship. Bloggers realized that they would receive little punishment except deletion of their posts. Such deletion might even serve as a "badge of honor" and help them gain followers. Censorship motivated these bloggers to continue writing on political topics. 


\section{$4 \quad$ Methods}

Interviews and document collection took place between April, 2014 and January, 2016. We studied several major political events in China, including the Umbrella Movement, the National People's Congress' plenary sessions, and the crackdown on government corruption in which high-profile government officials were arrested and sentenced. We recruited our interviewees on Weibo, the largest Chinese microblogging site. We first used keywords to locate online debates and conversations regarding the political events, identifying Weibo users who participated in relevant discussions. We then contacted these people through Weibo's private messaging function for an interview. We conducted 32 semi-structured, open-ended interviews with mainland Chinese residents. Participants included 19 males and 13 females between the ages of 18 and 46 (with an average age of 29). They included graduate students, government employees, editors, journalists, engineers, programmers, freelancers, and stock market traders. Our sample corresponds to the demographics of Weibo users who are educated and tech-savvy [57] and of course does not represent the whole Chinese population.

The first author, who conducted the interviews, is a native Chinese speaker. We asked participants to describe how they perceived Internet censorship in China, how they sought information about political events, and whether they experienced censorship. We asked participants to describe situations in which they encountered censorship, and how they dealt with it. With permission, we followed all participants' social media accounts. Some followed ours in return. The social media platforms included Weibo and popular online Chinese forums such as tianya.cn and Baidu Tieba. We read and archived participants' posts and comments which we triangulated with our interview data. All interview and social media data were translated into English by the first author. We use pseudonyms to protect participants' identities.

We followed a grounded theory approach [58] to analyze the data. We first read through the data, and then, through rounds of discussion, we identified broad themes. Using open coding, we identified specific patterns related to censorship. Once we had identified Confucianism as a theme, we found quotes in which participants' thoughts resonated with Confucian teachings or in which participants directly quoted words from Confucius. We present these quotes in the Findings section and develop discussion points to support our cultural analysis.

\section{$5 \quad$ Findings}

Participants deployed various strategies to circumvent censorship, consistent with what has been reported in previous studies [12, 15, 52, 59]. We discuss how participants encountered censorship and how they made decisions regarding censorship. 


\subsection{Censorship as Routine Experience}

Our participants explained that censorship sometimes had a negative impact on their online or offline activities. When asked how they dealt with these difficulties, they stressed the importance of adaptation. Adaptation was not to endure or accept with resignation, but to manage difficulties in a pragmatic and flexible manner, with the ultimate goal of living in harmony. Dealing with censorship became a routine practice in participants' daily lives, not something remarkable or with totalitarian overtones as it might be in other national contexts.

Almost all our participants said that they disliked censorship, citing the increased difficulties in information seeking and communication. Despite this unfavorable view, however, most $(\mathrm{n}=26)$ said that they did not consider censorship a major obstacle in their everyday online communication. They managed it in a smooth, routine fashion. For example, Leiyu, a 21-year-old college student, said:

The government blocks Facebook, Twitter, and some news websites. But it doesn't matter. A lot of Chinese are working and studying abroad. They share a lot of content on their Chinese social media accounts. I have two Weibo friends who live in Canada and post a lot of news. I don't really seek a lot of information that is classified as sensitive, but still I can get a lot just by following people on Weibo.

Participants felt that they generally enjoyed the freedom to obtain information and communicate ideas from the online venues they used. For ordinary online communication, censorship did not limit their ability to engage in conversation and share information. The Confucian ideal of harmony was a routine experience for our study participants; they did not feel stressed about their ability to find information or communicate. Maintaining a harmonious, non-confrontational relationship with other people and the government was a consistent goal mentioned in the interviews. Participants frequently referred to Confucius, quoting him to answer questions. For example, when we asked whether participants enjoyed encountering different opinions in online discussions, one answered, "The exemplary person is harmonious and open-minded to difference. The petty person can group easily but they do not stay together for long. 君子和而不同, 小人同而不和” [26]. When we asked about the ideal relationship between people with different opinions, they sometimes referred to Confucian teachings, “One should not impose on others what he himself does not desire. 己所不欲勿 施于人” [26].

Our participants discussed using word substitutes in their daily online communication to avoid words that might be censored, similar to previous studies' findings [6, 14]. However, participants said that in some cases, they did not use substitutes with the purpose of circumventing censorship, but as a way of rendering online conversation fun, casual, and hip. For example, Zhelu, a 37-year-old writer, said:

Many times it is not about escaping the sensitive keyword check. It is because

the young Internet generation devises a lot of new substitutes every day. I use these terms simply because it's more fun and more casual in online chat. It makes me feel young and fashionable.

Use of such word substitutes was an everyday routine practice that made communication more enjoyable. Matters of language are delicate; every utterance has more 
than one interpretation. The use of symbols such as the river crab does not necessarily denote a reaction to censorship, as Zhelu explained. We received similar responses from six other participants. Xuanwu, a 24-year-old graduate student, mentioned how he and his friends did not type in formal written Chinese, but used a lot of emoticons, punctuation, and even typos, for fun and word play. The use of substitutes functioned as a mundane action to sustain harmonious, playful communication. Previous studies emphasized word substitutes as a way to circumvent censorship. Our participants sometimes did that, but in many cases, the purpose of word substitutes was for delightful, entertaining communication.

Most participants $(n=27)$ found that mechanisms of censorship were not employed for every communication channel, but only a select set of online public venues and a particular set of topics, most of which concerned political events or government decisions. For example, Mingyue, a graduate student, noted:

I feel that the government does not or cannot monitor and control most of the online places I am using to speak with others. Me and my friends oftentimes say whatever we like in Weibo's reply area, WeChat, tianya, and baidu tieba. Sometimes the content can be pretty sensitive. But our conversations are never interrupted.

WeChat is the largest instant messaging tool in China. Like Mingyue, other participants experienced few interruptions caused by censorship in their daily communication regarding mundane topics. Censorship did not strike them as an obstacle to their online communication, compared to other circumstances they brought up in interviews, such as the difficulty of navigating a variety of information sources in search of desired information, or network speed.

\section{Deciding whether to circumvent censorship.}

All participants $(n=32)$ reported that they were aware that much of the information to which they had direct access had been examined, filtered, and altered by the government, consistent with other research [6, 60]. Leiyu said:

I visit Weibo every day. I follow more than one hundred accounts, which gives me many posts to read. However, I think I just read them for entertainment purposes. I glance through Weibo when I am having lunch alone. ... I think it is perhaps because I do not fully trust the information in the posts. The government or Weibo's administration team have censored and tailored a lot of it.

Leiyu was cautious with respect to what he was reading, and adjusted his expectations and subsequent interpretations of news he believed was filtered and modified by government censors. Awareness of censorship encouraged participants to be particularly cautious towards political news. Wen, another college student, told us:

I feel I know little about it [a political event], mostly because the central government has largely limited my right and ability to obtain information. If the government does not allow transparency, there is no truth.

Circumventing censorship was not the only choice available to our participants. The decision to circumvent, or not to, was based on participants' interests and time. Fifteen participants decided to circumvent based on the strength of their interest in specific information or events. They attempted to find as much information as possi- 
ble if events triggered strong interest. Otherwise, they would be content with the censored information. Leiyu described the process:

If I were interested in particular topics, such as the Umbrella Movement, I would rather check out original information in other venues.

Similarly, Cangqing, a 34-year-old engineer, described how his interest in the Umbrella Movement called for use of services such as Weibo and Baidu since he felt information on television was censored. He knew digital materials were also censored, but online venues offered him more opportunities to discover new knowledge, e.g., by using a variety of keywords, thus weakening the effect of censorship. Twentytwo participants mentioned that although some Chinese keywords were banned, their English equivalents were not (see Figure 1).

\begin{tabular}{|c|c|c|c|c|c|c|c|c|c|c|}
\hline \multirow{2}{*}{\multicolumn{2}{|c|}{ 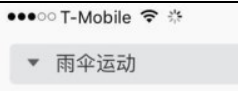 }} & & \multicolumn{2}{|c|}{ (․ $68 \%$} & \multirow{2}{*}{\multicolumn{2}{|c|}{$\cdots \bullet$ T-Mobile $\curvearrowright$}} & \multicolumn{3}{|c|}{ (ब $68 \%=$} \\
\hline & & & & 8 & Cancel & & & 8 & Canc & \\
\hline 综合＼cjkstart用户 & 精选 & 关注人 & 印象 & 主页 & 文 + & 综合＼cjkstart用户＼cjkstart精选 & 关注人＼cjkstart印象 & 主页 & 文 & + \\
\hline \multicolumn{6}{|c|}{$\begin{array}{l}\text { According to the relevant laws, regulations and } \\
\text { policies, the search results have not been } \\
\text { displayed. }\end{array}$} & \multirow{2}{*}{\multicolumn{5}{|c|}{$\begin{array}{l}\text { "毫不避讳而且有客观的反思" 这是所有课提到 } \\
\text { umbrella movement时我听到大家多面的有深度的 } \\
\text { 见解后的想法. 这里的学生的确比较active和 } \\
\text { talkative. }\end{array}$}} \\
\hline \multirow[t]{2}{*}{ 为你推荐 } & & & & & & & & & & \\
\hline & & & & & & $\square$ Repost & Comments & $\mathbb{8}$ & 1 & \\
\hline
\end{tabular}

Fig. 1. To the left is the English warning message for searching sensitive keyword (雨伞运动) in Chinese on Weibo, indicating that the Chinese word for the Umbrella Movement was banned on Weibo. The right side shows the results of searching sensitive keyword (Umbrella Movement) in English on Weibo, where the words were not banned. The first author performed these two searches on his smartphone after an interviewee mentioned this phenomenon.

Many participants $(n=21)$ chose to follow particular stories of interest to them in which they would invest more time. Ming, a 26-year-old programmer, said:

There are too many important political issues worth my attention, such as the economic bubble, the Asian Infrastructure Investment Bank, and the National People's Congress. I cannot really spend the equal amount of time and effort studying every single event... There are priorities. For events with lower priority, I am fine with just reading the state media. I do not necessarily trust what the state media says. For news that I am really interested in, I will definitely climb the wall and see what Western media says.

Ming's response represented a common strategy of ignoring censorship when news events were not of significant interest. When participants did want to know more, they found ways to do so. This strategy aligns with Confucian philosophy-people were pragmatic with respect to how they dealt with and viewed censorship and made decisions about when to just live with it. The choice of circumventing or not was subject to participants' agendas and interests. 
Our participants viewed censorship as one constraint, among the many other constraints they dealt with in their lives on a daily basis. They followed a flexible and situational decision making process in managing censorship.

\subsection{Seeing Advantages and Disadvantages of Censorship}

Participants $(n=21)$ refrained from denouncing censorship as purely evil and repressive. In fact, they found some value in the restraints it imposes. They expressed concern regarding the dangers of an uncontrolled flow of information, particularly rumors. Cheng, a 30-year-old accountant, noted:

I have found that rumors often cause a lot of troubles in China. People are panicked easily. For example, recently there was a rumor on Weibo that a group of human traffickers secretly moved to my hometown. Suddenly all the parents began to pick up their children. They waited outside school gates and blocked the local traffic for hours. Later it turned out that this was a false rumor made up by a random high school student who was bored one day. So yeah, I think the government should take more responsibility in monitoring this kind of online information.

Similar concerns with resolving rumors were voiced by twenty other participants. They stressed that the government should deploy sensible strategies when managing the Internet. This attitude signifies a trust in paternalistic structures that give the government considerable agency in utilizing censorship strategies considered best for the country. This attitude reflects participants' consideration of the Confucian virtue of propriety which explicitly attaches importance to the maintenance of the existing hierarchy and the rule of the government.

Participants held cautious attitudes towards expressing online opinions but not because of censorship. Situ, a 23-year-old government employee, said:

I see a lot of people making immediate, rash comments after reading one single piece of news. They do not even know whether it is true or not. Does this do any good to our online space and our society? Is this really the so-called freedom of speech? I think this is nothing but irresponsible.

Similarly, Xiaotu, a 32-year-old editor, reflected on her own online behavior:

I used to be a student. I fully understand that students are emotional and do not apprehend public issues in an objective and comprehensive way. When I was in middle and high school, I admired Western societies a lot. I thought every aspect of Western society was better than that of China. Whenever there was a certain terrible public issue, I blamed the Chinese government... [Now] I am grateful for my college education. I learned a lot about our history and society during that time. Now I have a mature mind. I try to understand those issues rather than rushing to blame China. I see many Weibo users speak in the exact same way I did as a high school student. They easily make accusations that someone is part of the 50-cent party or that they are brainwashed. Their minds are still immature, but they will eventually grow up in the future.

Many participants $(\mathrm{n}=18)$ acknowledged the utilitarian value of digital technologies in facilitating expression. However, they were worried about the irresponsible use of these technologies in the name of freedom of speech. They wanted to include 
consideration of the negative side of online debates in their assessment of freedom of speech and censorship, articulating a desire for careful, harmonious communication, consistent with Confucian teachings. When describing their perceptions of censorship, participants often emphasized peaceful, harmonious online communication, using a Confucian saying: “Harmony is the most precious. 和为贵” [26]. For example, one participant said, "I do not like to argue with others online. This often ends up nowhere. People should treat each other in a nicer way. After all, harmony is the most precious."

Many participants $(n=23)$ commented on international conflicts between China and other countries, endorsing certain of the Chinese government's actions to regulate online speech in China to manage international tensions. As Xuanwu noted:

Our Internet is already in chaos. The Chinese government is not the only one having paid commentators, for sure. Western governments and others are also hiring people to create and circulate opinions about democratizing China or colonizing China again. They probably want a Chinese version of the Arab Spring. I believe censorship is necessary to resist some of these influences.

Participants $(n=22)$ agreed that the government is responsible for shepherding use of the Internet, a paternalistic notion derived from Confucianism. Gushi, a 46-yearold stock market trader, discussed how censorship directed online discussion in a constructive way:

Young people are relatively reckless and idealistic. When they have lived for more than 40 years, they will gain a comprehensive understanding of both society and life. At that point, they will begin to think about public issues in a mature way... However, young people are occupying the Internet. Their time and energy should be better spent on their own work and life. Putting a barrier on their online activity is not necessarily a bad thing.

However, approving of certain acts of censorship did not mean that participants agreed with every aspect and practice of censorship perpetrated by the government. Tang, 35-year-old government employee, said:

Censorship is a necessary mechanism to protect societal stability and harmony.

There is no absolute freedom of speech. If the government does not rein in what circulates on the Internet, a lot of public issues can easily spiral out of control. However, I do think censorship's current shape is a bit too strict. For example, some keywords can suddenly become unsearchable for no obvious reason.

A graduate student expressed her dissatisfaction with the strictness of Chinese censorship. She said:

Although I can see the point in censorship, it is sometimes too strict. For instance, a while ago I wrote a blog with hundreds of words. But I could not submit it because the blog site said the blog contained some sensitive keyword. I checked the whole blog again and again but failed to find any sensitive word. Eventually I had to give up. I simply don't understand why it has to be so strict. What harm can that blog do?

Participants had expectations regarding the appropriate degree of strictness that should be applied. In many cases, the current degree was deemed overly strict. 
Participants' attitudes towards censorship seem contradictory. On the one hand, participants showed a somewhat accepting attitude towards censorship in pointing out its advantages, and stressing the government's responsibility to manage the Internet. On the other hand, participants saw that censorship hindered some of their online experiences. Their attitudes reflected acceptance of a paternalistic social order that attaches a strong expectation of responsibility for the common weal to the government. However, this acceptance did not mean that participants could not have their own ideas regarding governance or be frustrated at certain government actions.

\subsection{Developing Skills of Circumvention}

Confucius believed that the resources a person is entitled to should equal the person's capacities, or wisdom. Otherwise, the person not only wastes resources, but may also abuse the resources. Our online observations and interviews with participants revealed a similar belief, namely, that the amount of information a person can access should be commensurate with their abilities.

In online discussions on social media, we often came across people debating the influence of censorship over freedom of speech. Here is an excerpt from a conversation on Weibo:

Gangli: Mainlanders are confined in cages. We know nothing besides what the government wants us to know.

Yuyi: How would you define cage? In fact, the government does not confine people. Only people can confine themselves. How do you expect a person to jump out of the box if he only reads party newspapers every day? If you cannot think for yourself, how can climbing the wall help? It does nothing except put new biases into your head.

Yuyi dismissed the idea that censorship is an overwhelming obstacle that prevents people from obtaining information. She emphasized individual agency as the key to understanding public events. Gangli, however, used strong imagery to describe what he considered excessive government control. Without "thinking for yourself," consuming more information does not help. "[P]eople should develop the ability of critical thinking," said Gushi. He quoted Confucius in saying that "learning without thought means labor lost. 学而不思则風.” In other words, the individual bears responsibility for behaving pragmatically and sensibly.

Our participants $(\mathrm{n}=22)$ often described circumvention of censorship as a personal choice. Leng, a 29-year-old office worker, said:

I find the idea of brainwashing funny. Even in the Chinese media, there are so many sources with very different information and opinions. The government cannot

really ban them all. You can find them only if you want to. Otherwise, even if you live in the West with many, many media choices, you can still be very narrowminded.

Leng and many other participants stressed the importance of individual agency in managing censorship. For them, exposure to information did not guarantee insight or knowledge. The ability to understand and reflect on information was more important. 
Participants $(n=17)$ associated circumvention practices with the willingness to learn. Guzi, a 29-year-old graduate student, remarked:

I think it's not that hard to use VPN tools or proxy servers to visit Facebook or Twitter. Any person with basic computer knowledge can learn it, as long as they are willing to.

Participants associated finding filtered, sensitive information with just doing a bit of extra work. They recognized the extra effort required to find information in certain circumstances, and believed that it was up to them to do it if they so desired.

When asked how they managed censorship, 28 participants stressed mastering know-how of general strategies rather than the specific technical means of circumvention. For them, it was important to be flexible and to be able to adapt to new techniques as well as new information sources. For example, Leiyu explained:

It's not about knowing which specific site to find certain information. After all, that site can be gone any time. The point is to know how you can find the site containing desired information.

Li, a 24-year-old graduate student, elaborated on what constitutes know-how:

You have to keep your mind open to new tools and browsing new websites. New tools can always surprise you! My friend once introduced a website storing a lot of YouTube videos. I'm sure a lot of them are forbidden in China. I was amazed by its rich content.

As we have noted, previous work has shown the numerous ways Chinese citizens bypass censorship $[6,14,59]$. Here we emphasize participants' flexibility in adopting and learning new tools and finding new resources in order to expand their knowledge, as well as their pragmatic attitude towards censorship, and their willingness to help others find the information they need.

Participants sympathized with like-minded people who wanted more information. Many reported practices of sharing information with others, even strangers. Zi, a 29year-old graduate student, explained her willingness to share information, saying:

I do not mind sharing sensitive information with people online, even if I do not

know them. This is because I fully understand how it feels when you desire some information. In the past, somebody shared information with me as well.

We asked participants whether and why they were willing to share sensitive information. Xingxi laughed and quoted Confucius, saying that "a good person is always ready to help others attain their aims. 君子成人之美” [26]. He further asked, “Why shouldn't I send out the information if it helps others and does me no harm?'

Participants linked circumventing censorship to their own sensible, resourceful practices. Managing censorship is much like managing other aspects of life for Chinese citizens. Acts of circumvention do not connote a deep refusal of government initiatives as they might in the West. On the contrary, they allow citizens to find what they want to know, while still observing the appropriateness of hierarchy as formulated in Confucian principles. 


\subsection{Summary}

Our participants emphasized a willingness and capacity to deal with censorship and obtain information. Participants agreed that the information a person could access depended on his or her own capacity and effort. Such a view not only reflects flexibility and pragmatism in dealing with constraints, but also the deep-rooted Confucian values regarding how resources should be distributed in society.

\begin{tabular}{|c|l|}
\hline & What participants said they thought or did \\
\hline Attitudes & $\begin{array}{l}\text { Supported censorship for societal stability }(2,3) \\
\text { Criticized censorship for blocking information }(2,5)\end{array}$ \\
\hline Practices & $\begin{array}{l}\text { Consumed censored information }(3,4) \\
\text { Circumvented censorship to obtain desired information }(1,2,3,4)\end{array}$ \\
\hline
\end{tabular}

Table 1. Links between participants' attitudes and practices and the five virtues. $1=$ benevolence, 2 = righteousness, 3 = propriety, $4=$ wisdom, 5 =integrity.

Table 1 summarizes the links between participants' attitudes and practices in relation to the five virtues in Confucianism. Participants saw advantages to censorship in maintaining societal stability, resonating with righteousness, propriety, and integrity, as they agreed that censorship was correct in maintaining propriety. They did not shy away from criticizing the government for its strictness in censorship, showing their sense of righteousness and integrity. Participants consumed censored information as they respected propriety, and believed that even censored information could contribute to their knowledge and wisdom. They shared information with strangers, manifesting the virtue of benevolence and righteousness. They emphasized circumvention rather than protest and confrontation, respecting propriety.

\section{Discussion}

Few studies have explored the ways in which Chinese citizens view and experience censorship. Through a qualitative study of Chinese citizens' attitudes toward and practices of censorship, we discovered the routineness of managing censorship, and the acceptance and approval of certain forms of censorship. These findings conflict in some important ways with mainstream thoughts regarding censorship, such as the United Nations' declaration of Internet access as a basic human right [61]. We argue that it is important to understand censorship practices by drawing connections to the specific historical national context.

We have traced participants' attitudes toward censorship to the ancient teachings of Confucianism. Ample research has documented that contemporary Chinese citizens continue to seek to cultivate themselves through reading Confucius' classic works and through following the doctrines of Confucianism [21-23, 62-64]. Our work is interpretive, drawing on our knowledge of Confucianism in the Chinese context. Without this larger situated framing, we cannot explain actions that seem contradictory. It is within the larger philosophical system of Confucianism with its emphasis on harmo- 
ny, pragmatism, and paternalism that participants' responses to censorship become logical and comprehensible.

Our study participants' attitudes and practices manifested the Confucian virtues in concrete ways. Participants valued benevolence and propriety over confrontation in relations with others. They chose to accept censorship as a circumstance, and to explore alternatives to bypassing it, rather than subverting it. They made individual choices to obtain sensitive information in order to improve their own righteousness, wisdom, and integrity. They were willing to share sensitive information with others who expressed need. At the same time, participants placed considerable responsibility for and trust in the government to manage the public sphere. Acts of circumvention and sharing sensitive information with others did not connote the kind of ideological and practical resistance to and rejection of government actions that they might connote in other sociohistorical contexts.

Our contributions to the HCI literature are three-fold: First, we contribute to the information seeking literature by presenting a nuanced and culturally-situated analysis of information seeking practice in a heavily-censored environment. Second, the study develops a situated, emic interpretation of censorship that is still missing in the literature. Third, our contribution lies in using Confucianism as an interpretive lens to analyze contemporary Chinese technology practices.

\subsection{Citizens and Censorship in China}

Previous work has tended to frame censorship as a repressive, top-down tool employed by the Chinese government $[6,19,51,60,65,66]$. Our investigation points to the role of Chinese citizens themselves in the formation, maintenance, and development of censorship. Participants' tolerance of and compliance with censorship stands in sharp contrast to research that assumes that Chinese citizens should resist and rebel. Our study participants reported that they would engage in confrontations with the Chinese government only under the most extreme circumstances. For example, one participant said that he would "participate in collective actions if government decisions threaten normal life, such as building chemical plants too close to a residential area." Participants' common strategy was to adapt, and to find ways to overcome problems quietly. If they could not solve the problems, they preferred to endure, survive, and succeed in their endeavors by turning their attention to other matters in life.

We thus suggest the importance of considering the cultural and sociohistorical dimensions of censorship. In China, certain circumstances such as Confucian values and beliefs existed before censorship and before the current regime that exercises it. While our study brings attention to the consequences of Confucianism on censorship practices and attitudes, we do not exclude possible connections between censorship and other Chinese cultural elements such as Taoism and Buddhism. These would require further study. We have noted participants' acceptance of certain Western liberal forms of civic engagement such as public deliberation. Participants acknowledged the power of collective action in influencing government decisions. Chinese citizens' attitudes and practices are in a state of flux, and yet they are, at the same time, informed by a 
venerable tradition that has lasted for millennia. Fundamental changes will take time to emerge, and as they evolve, they will be informed by Chinese history and society.

\subsection{Expanding the Paradigm for Research in Civic Engagement and Politics}

Developed within Western universities and corporations, much HCI research on civic engagement and politics has naturally followed conventions of democratic traditions in assessing how digital technologies can contribute to the betterment of society [67-69]. This paradigm is evident in studies of online political deliberation [70-72], social movements [73-76], local community engagement [77-82], citizen news generation and news seeking behaviors [83, 84], and citizen participation in political campaigns $[85,86]$. These studies highlight the culture of participatory democracy in which ordinary citizens can and should engage in discussion of public issues. In contrast, contemporary China follows a paternalistic model of governance. Consequently, even actions such as circumvention that appear to meet Western expectations, might actually have different rationales for Chinese citizens. Our findings indicate that circumvention and sharing sensitive information in the Chinese context connote not an attitude of subversion, nor of opposition to censorship, but a pragmatic, routine, utilitarian means of obtaining desired information.

We argue that censorship and its related attitudes and practices can be better understood if we consider specific national contexts. The significance of linking censorship to its sociohistorical context speaks to several critical strands of related work, such as postcolonial computing [67], feminist HCI [87], and political economy in HCI [88]. Postcolonial computing examines how research and design can be understood as "culturally located and power laden." Feminist HCI provides a critical perspective for looking at the existing body of knowledge about censorship as primarily situated in the Western context. Political economy indicates that technology is embedded in the wider political economy and is not intelligible without consideration of that political economy. These perspectives are developing as crucial resources that are beginning to shift the paradigm in HCI. We favor taking them into account as much as possible as we move forward. We attempted to do so in our analysis by situating seemingly contradictory findings about Chinese attitudes toward censorship in a sociopolitical context with deep roots in the ethical system of Confucianism, examining this system as it plays out in the politics of contemporary China.

\subsection{Design for What Purpose?}

Viewing censorship as a "problem," researchers and practitioners have devised and implemented solutions to resist or bypass censorship [89-92]. However, framing the current situation as a set of "problems" and technological systems as "solutions," can be misleading [93]. Baumer and Silberman discussed when not to design, suggesting how a specific situation can constitute "a complex and multifaceted condition with which we must grapple" [93]. Pierce discussed the value of "undesign" in response to concerns with the limitations and negative effects of technology [94]. Our findings about censorship in China are in harmony with the arguments of these scholars. Cen- 
sorship in the Chinese context cannot be framed as a problem to be solved. It is a substantial element of China's complex online context co-created by citizens and the government. Design for the demolition of censorship is infeasible, and out of step with the realities of China's current sociopolitical system, as well as its lengthy history as a nation state.

We see Confucianism as a source of inspiration for design in a Chinese cultural context. While an in-depth analysis of how Confucianism can be useful for design is out of the scope of this paper, and our chief objective was to present our empirical material, we provide some preliminary suggestions. The five virtues offer insights into design values that could guide future development. For example, the virtue of wisdom stresses individuals' pursuit of knowledge and information. Our participants developed better understandings of the advantages and disadvantages of each media source, as well as censored information, in order to make better judgments about a public event. Still, they acknowledged that limited time and energy prevented them from getting the full picture of an event, and they were aware that they were consuming imperfect information. Social media, for example, might offer recommendation functions to suggest news from outside the participant's usual sources, or point to the blogs or Twitter feeds of people who hold different views.

The virtues of righteousness and integrity indicate individual responsibility for people's own online behavior. Participants criticized those who made rash comments and emphasized the need for careful thought. Today's social media design often encourages users to take rapid actions such as clicking "likes" or retweeting. The speed encouraged by social media shifts activity away from deliberate, careful reflection. It is time to rethink the relationship between how we design social media and individual responsibility, particularly in light of public events. Design might consider means of encouraging critical thinking before people take actions. DiSalvo argued that design can provoke reactions and actions via identification and articulation of public issues [68]. He pointed to two design tactics: projection, which presents possible future consequences associated with an issue, and tracing, which documents and makes known the assemblage of materials, concepts, and ideas that impact an issue over time. Such approach might be useful in the Chinese context. Participants' emphasis on choice and mastering know-how indicates the value of techniques that provide rich, diverse information. For example, using the projection tactic, design might present possible environmental consequences alongside a product.

\subsection{Implications for HCI Studies of China}

To date, most HCI studies of China adopt terminology or theories with a Western perspective. Such an approach risks diminishing cultural differences of critical importance [69]. For example, the word censorship belongs to the everyday vocabulary of the West, but its Chinese equivalent, “审查制度,” is not an everyday word, and did not occur within our interviews. To ask censorship-related questions, the first author approached interviewees with a variety of terms such as "blocking website," "post deletion," and "account suspension" which were more familiar to participants. From a sociolinguistic perspective [95], this usage indicates that censorship plays a different, 
and less prominent, sociocultural role than in the West. Our work demonstrates the value of drawing from a localized perspective to develop emic interpretations of what people think and do.

Utilizing a Confucian lens to interpret Chinese citizens' technology practices has important implications for HCI studies of China. We showed that the five virtues are a useful basis for HCI work in China that concerns individuals' behavioral and thinking patterns, as well as Chinese social practices ranging from communication, to coordination, to organization. For example, benevolence and propriety are relevant in analyzing interpersonal communication and organizational communication where people follow certain norms and etiquettes to treat each other in proper ways. Righteousness and integrity are pertinent in exploring the connections between individuals' actions and thoughts. Wisdom can be deployed to interpret how individuals seek to cultivate their own personality, knowledge, and skill in work and life.

\section{CONCLUSION}

We presented a qualitative study exploring how Chinese citizens perceive and manage Internet censorship. Participants had nuanced attitudes and practices that did not resolve to simple "for" or "against" behaviors and practices with respect to censorship. We showed how participants' actions were consistent with the classic teachings of Confucianism. We caution against judging whether censorship is "positive" or "negative" in all contexts, and we caution against simple binary design suggestions for or against censorship. We highlight the role of particular sociohistorical contexts in influencing the formation and maintenance of censorship. Specific contexts determine how people develop ways to think about and act within their own circumstances.

\section{ACKNOWLEDGEMENTS}

We are grateful to our participants for sharing their practices around censorship and offering candid thoughts about China's censorship. We thank Xinning Gui for early discussions of the Confucian framework. We thank the anonymous reviewers at INTERACT'2017 for their constructive and insightful feedback that helped strengthen the paper, as well as their open-mindedness to this paper's findings and interpretive perspective which is different from the dominant view of censorship in the West.

\section{References}

1. Poller, A., Ilyes, P., Kramm, A., Kocksch, L.: Investigating OSN users' privacy strategies with in-situ observation. CSCW Companion '14. pp. 217-220. ACM Press (2014).

2. Semaan, B.C., Britton, L.M., Dosono, B.: Transition Resilience with ICTs: "Identity Awareness" in Veteran Re-Integration. CHI '16. pp. 2882-2894. ACM Press (2016).

3. Sleeper, M., Balebako, R., Das, S., McConahy, A.L., Wiese, J., Cranor, L.F.: The post that wasn't: exploring self-censorship on facebook. CSCW '13. pp. 793-802. ACM Press (2013). 
4. Wisniewski, P., Lipford, H., Wilson, D.: Fighting for my space: coping mechanisms for sns boundary regulation. CHI '12. pp. 609-618. ACM Press (2012).

5. Liang, B., Lu, H.: Internet Development, Censorship, and Cyber Crimes in China. J. Contemp. Crim. Justice. 26, 103-120 (2010).

6. MacKinnon, R.: China's "Networked Authoritarianism," (2011).

7. Kuutti, K., Bannon, L.J.: The turn to practice in HCI: towards a research agenda. CHI '14. pp. 3543-3552. ACM Press (2014).

8. Bamman, D., O'Connor, B., Smith, N.: Censorship and deletion practices in Chinese social media. First Monday. 17, (2012).

9. Hachigian, N.: China's cyber-strategy. Foreign Aff. 80, 118 (2001).

10. Ng, J.Q., Landry, P.F.: The Political Hierarchy of Censorship: An Analysis of Keyword Blocking of CCP Officials' Names on Sina Weibo Before and After the 2012 National Congress (S)election. (2013).

11. Stockmann, D., Gallagher, M.E.: Remote Control: How the Media Sustain Authoritarian Rule in China. Comp. Polit. Stud. 44, 436-467 (2011).

12. Givens, J.W., MacDonald, A.W.: The Internet with Chinese Characteristics: Democratizing Discourse But Not Politics. In: APSA 2013 Annual Meeting. p. 19 (2013).

13. Poell, T., de Kloet, J., Zeng, G.: Will the real Weibo please stand up? Chinese online contention and actor-network theory. Chinese J. Commun. 7, 1-18 (2013).

14. Rauchfleisch, A., Schäfer, M.S.: Multiple public spheres of Weibo: a typology of forms and potentials of online public spheres in China. Information, Commun. Soc. 1-17 (2014).

15. Yang, G.: The Co-evolution of the Internet and Civil Society in China. Asian Surv. 43, 405-422 (2003).

16. Shklovski, I., Kotamraju, N.: Online contribution practices in countries that engage in internet blocking and censorship. In: CHI '11. pp. 1109-1118. ACM Press (2011).

17. Sima, Q.: Records of the Grand Historian of China. Zhonghua Book Company, Beijing (1959).

18. Weber, M., Gerth, H.H.: The Religion of China, Confucianism and Taoism. (1953).

19. Wang, D., Mark, G.: Internet Censorship in China: Examining User Awareness and Attitudes. ACM Trans. Comput. Interact. 22, 1-22 (2015).

20. Dong, Z.: The Luxuriant Dew of the Spring and Autumn Annals. Zhonghua Book Company, Beijing (2011).

21. Bell, D.A.: China's New Confucianism: Politics and Everyday Life in a Changing Society. Princeton University Press (2010).

22. Bell, D.A.: Reconciling Socialism and Confucianism?: Reviving Tradition in China. Dissent. 57, 91-99 (2009).

23. Fukuyama, F.: Confucianism and Democracy, (1995).

24. Yum, J.O.: The impact of Confucianism on interpersonal relationships and communication patterns in east Asia. Commun. Monogr. (2009).

25. Mencius: Mencius. Zhonghua Book Company, Beijing (2010).

26. Confucius: The Analects. Zhonghua Book Company, Beijing (2006).

27. Zhu, X.: The Analects of Confucius Variorum. (1200).

28. Xunzi: Xunzi: The Complete Text. Princeton University Press (2014).

29. Wang, Z., Pavlićević, D.: Citizens and Democracy: Shi Tianjian's Contribution to China Studies and Political Science. China An Int. J. 10, 125-135 (2012).

30. Shi, T.: Cultural Values and Political Trust: A Comparison of the People's Republic of China and Taiwan. Comp. Polit. 33, 401-419 (2001).

31. Shi, T.: Political Participation in Beijing. Harvard University Press (1997).

32. Shi, T., Lu, J.: The Shadow of Confucianism. J. Democr. 21, 123-130 (2010). 
33. Shi, T.: China: Democratic Values Supporting an Authoritarian System. In: Chu, Y., Diamond, L., Nathan, A.J., and Shin, D.C. (eds.) How East Asians View Democracy. Columbia University Press (2008).

34. Nathan, A.J., Shi, T.: Cultural Requisites for Democracy in China: Findings from a Survey. Daedalus. 122, 95-123 (1993).

35. Li, S.: The online public space and popular ethos in China. Media, Cult. Soc. 32, 63-83 (2010).

36. Tsui, L.: The Panopticon as the Antithesis of a Space of Freedom: Control and Regulation of the Internet in China. China Inf. 17, 65-82 (2003).

37. Roberts, M.: Experiencing Censorship Emboldens Internet Users and Decreases Government Support in China. (2015).

38. Cheung, A.S.Y.: The Business of Governance: China's Legislation on Content Regulation in Cyberspace. Int. Law Polit. 38, 1-37 (2006).

39. Human Rights Watch: China: Nationwide Arrests of Activists, Critics Multiply, http://www.hrw.org/news/2013/08/30/china-nationwide-arrests-activists-critics-multiply.

40. King, G., Pan, J., Roberts, M.: How Censorship in China Allows Government Criticism but Silences Collective Expression. Am. Polit. Sci. Rev. 107, 326-343 (2013).

41. Ebbs, G., Rheingold, H.: Censorship on the Information Highway. Internet Res. 7, 59-80 (1997).

42. Lawson, T., Comber, C.: Censorship, the Internet and schools: a new moral panic? Curric. J. 11, 273-285 (2000).

43. Ang, P.H., Nadarajan, B.: Censorship and the Internet: a Singapore perspective. Commun. ACM. 39, 72-78 (1996).

44. Bambauer, D.E.: Filtering in Oz: Australia's Foray into Internet Censorship. Univ. Pennsylvania J. Int. Law. 31, (2009).

45. Pater, J.A., Haimson, O.L., Andalibi, N., Mynatt, E.D.: "Hunger Hurts but Starving Works:" Characterizing the Presentation of Eating Disorders Online. In: CSCW '16. pp. 1183-1198. ACM Press (2016).

46. Gillespie, T.: Can an Algorithm be Wrong? Limn. 1, (2012).

47. Wilson, T.: On user studies and information needs. J. Doc. 37, 3-15 (1981).

48. Behrouzian, G., Nisbet, E.C., Dal, A., Çarkoğlu, A.: Resisting Censorship: How Citizens Navigate Closed Media Environments. Int. Journal of Commun. 10, 23 (2016).

49. Gunther, A.C., Snyder, L.B.: Reading International News in a Censored Press Environment. Journal. Mass Commun. Q. 69, 591-599 (1992).

50. Cherry, S.: The net effect: as China's Internet gets a much-needed makeover, will the new network promote freedom or curtail it? IEEE Spectr. 42, 38-44 (2005).

51. MacKinnon, R.: Flatter world and thicker walls? Blogs, censorship and civic discourse in China. Public Choice. 134, 31-46 (2007).

52. Nardi, B.: Virtuality. Annu. Rev. Anthropol. 44, (2015).

53. Kou, Y., Kow, Y.M., Gui, X.: Resisting the Censorship Infrastructure in China. In: 2017 50th Hawaii International Conference on System Sciences. pp. 2332-2340 (2017).

54. Jiang, M.: The Co-Evolution of the Internet, (Un)Civil Society \& Authoritarianism in China. In: The Internet, Social Media, and a Changing China. University of Pennsylvania Press, Philadelphia, PA (2014).

55. Mina, A.X.: Batman, Pandaman and the Blind Man: A Case Study in Social Change Memes and Internet Censorship in China. J. Vis. Cult. 13, 359-375 (2014).

56. Yang, G., Jiang, M.: The networked practice of online political satire in China: Between ritual and resistance. Int. Commun. Gaz. 77, 215-231 (2015).

57. Weibo: 2014年微博用户发展报告. (2014). 
58. Corbin, J., Strauss, A.: Basics of Qualitative Research: Techniques and Procedures for Developing Grounded Theory. SAGE Publications (2007).

59. Mou, Y., Wu, K., Atkin, D.: Understanding the use of circumvention tools to bypass online censorship. New Media Soc. 18, 837-856 (2014).

60. Leibold, J.: Blogging Alone: China, the Internet, and the Democratic Illusion?, (2011).

61. La Rue, F.: Report of the Special Rapporteur on the promotion and protection of the right to freedom of opinion and expression. (2011).

62. Bol, P.K.: Neo-confucianism in history. Harvard University Press (2010).

63. Fan, R., Yu, E.: The renaissance of Confucianism in Contemporary China. Springer Science \& Business Media (2011).

64. Melvin, S.: Yu Dan and China's return to Confucius, (2007).

65. Li, Y.: Smart Censorship in China Weibo: An Industry and Party-State Double Act. SSRN Electron. J. (2013).

66. Wang, W.Y.: Who's blocking the Chinese Internet? The rise of cybercultures and the generational conflicts in China, In Baumann, Sabine (Ed.) Cybercultures: Cultures in Cyberspace Communities. pp. 145-166. Inter-Disciplinary Press (2012).

67. Irani, L., Vertesi, J., Dourish, P., Philip, K., Grinter, R.E.: Postcolonial computing: a lens on design and development. CHI '10. pp. 1311-1320. ACM Press (2010).

68. Khosrow-Pour, M.: Encyclopedia of Information Science and Technology, Third Edition. IGI Global (2014).

69. Nardi, B., Vatrapu, R., Clemmensen, T.: Comparative informatics. interactions. 18, 28 (2011).

70. Semaan, B., Faucett, H., Robertson, S.P., Maruyama, M., Douglas, S.: Designing Political Deliberation Environments to Support Interactions in the Public Sphere. CHI '15. pp. 3167-3176. ACM Press (2015).

71. Bohøj, M., Borchorst, N.G., Bødker, S., Korn, M., Zander, P.-O.: Public deliberation in municipal planning: supporting action and reflection with mobile technology. C\&T '11. p. 88. ACM Press (2011)

72. Semaan, B., Robertson, S., Douglas, S., Maruyama, M.: Social media supporting political deliberation across multiple public spheres: towards depolarization. CSCW '14. pp. 14091421. ACM Press (2014).

73. Crivellaro, C., Comber, R., Bowers, J., Wright, P.C., Olivier, P.: A pool of dreams: facebook, politics and the emergence of a social movement. CHI '14. pp. 3573-3582. ACM Press (2014).

74. Dimond, J.P., Dye, M., Larose, D., Bruckman, A.S.: Hollaback!: the role of storytelling online in a social movement organization. CSCW '13. pp. 477-489. ACM Press (2013).

75. Roeder, M.: Social movements using social media in a mined and censored world: examples in the United States and China, http://via.library.depaul.edu/etd/156, (2013).

76. Kow, Y.M., Kou, Y., Semaan, B., Cheng, W.: Mediating the Undercurrents: Using Social Media to Sustain a Social Movement. CHI '16. pp. 3883-3894. ACM Press (2016).

77. Le Dantec, C.A., Edwards, W.K.: Designs on dignity:perceptions of technology among the homeless. CHI '08. pp. 627-636. ACM Press, New York, USA (2008).

78. DiSalvo, C.: Design and the Construction of Publics. Des. Issues. 25, 48-63 (2009).

79. DiSalvo, C., Light, A., Hirsch, T., Le Dantec, C.A., Goodman, E., Hill, K.: HCI, communities and politics. CHI EA '10. pp. 3151-3154. ACM Press (2010).

80. Gordon, E., Baldwin-Philippi, J., Balestra, M.: Why We Engage: How Theories of Human Behavior Contribute to Our Understanding of Civic Engagement in a Digital Era. SSRN Electron. J. (2013). 
81. Kavanaugh, A., Carroll, J.M., Rosson, M.B., Reese, D.D., Zin, T.T.: Participating in civil society: the case of networked communities. Interact. Comput. 17, 9-33 (2005).

82. Kavanaugh, A., Carroll, J.M., Rosson, M.B., Zin, T.T., Reese, D.D.: Community Networks: Where Offline Communities Meet Online. J. Comput. Commun. 10, 00-00 (2005).

83. Monroy-Hernández, A., Boyd, D., Kiciman, E., De Choudhury, M., Counts, S.: The new war correspondents: the rise of civic media curation in urban warfare. In: CSCW '13. pp. 1443-1452. ACM Press (2013).

84. Wang, Y., Mark, G.: Trust in Online News: Comparing Social Media and Official Media Use by Chinese Citizens. CSCW '12. pp. 599-610. ACM Press (2013).

85. Gayo-Avello, D.: Don't turn social media into another "Literary Digest" poll. Commun. ACM. 54, pp. 121-128 (2011).

86. Kriplean, T., Morgan, J., Freelon, D., Borning, A., Bennett, L.: Supporting reflective public thought with considerit. CSCW '12. pp. 265-274. ACM Press (2012).

87. Bardzell, S.: Feminist HCI: taking stock and outlining an agenda for design. CHI '10. pp. 1301-1310. ACM Press (2010).

88. Ekbia, H., Nardi, B.: Social Inequality and HCI: The View from Political Economy. In: CHI '16. pp. 4997-5002. ACM Press (2016).

89. Burnett, S., Feamster, N., Vempala, S.: Chipping Away at Censorship Firewalls with UserGenerated Content. In: USENIX Security Symposium. pp. 463-468 (2010).

90. Feamster, N., Balazinska, M., Wang, W., Balakrishman, H., Karger, D.: Thwarting Web Censorship with Untrusted Messenger Discovery. In: Dingledine, R. (ed.) Privacy Enhancing Technologies. pp. 125-140. Springer Berlin Heidelberg (2003).

91. Serjantov, A.: Anonymizing Censorship Resistant Systems. In: Druschel, P., Kaashoek, F., and Rowstron, A. (eds.) Peer-to-Peer Systems. pp. 111-120. Springer (2002).

92. Waldman, M., Mazières, D.: Tangler: a censorship-resistant publishing system based on document entanglements. In: CCS '01. pp. 126-135. ACM Press (2001).

93. Baumer, E.P.S., Silberman, M.S.: When the implication is not to design (technology). In: CHI '11. pp. 2271-2274. ACM Press (2011).

94. Pierce, J.: Undesigning technology: considering the negation of design by design. In: CHI '12. pp. 957-966. ACM Press (2012).

95. Tausczik, Y.R., Pennebaker, J.W.: The Psychological Meaning of Words: LIWC and Computerized Text Analysis Methods. J. Lang. Soc. Psychol. 29, 24-54 (2010). 